\title{
Factors Influencing the Growth of Small-Scale Restaurants in Nakuru Municipality-Kenya
}

\author{
*E. w nyoike, L.C Langat ${ }^{1}$, L.M. Karani ${ }^{2}$, A.C. Lagat $^{3}$ \\ Laikipia University, Kenya
}

\begin{abstract}
Small and Medium Enterprises (SMEs) comprise the largest proportion of business in most developing economies and frequently offer the largest potential for job creation. A great deal of research has been undertaken in the area of small businesses noting that most of the jobs are created through SMEs and selfemployment. SMEs are regarded as an essential element of economic growth; however, the number of small enterprises that grow in terms of number of employees and turnover are very few the purpose of this study therefore was to investigate the factors that influence the growth of small-scale restaurants in Nakuru municipality. The research method used in this study was a survey. A sample of 80 restaurants was selected using stratified random sampling. Using personally administered questionnaire, data was collected from restaurants managers/owners. Data analysis was done using both qualitative and quantitative methods. The findings of the study indicate that small - scale restaurants in Nakuru Municipality have been growing in terms of the number of employees, turnover and expenses. The growth of the restaurants is mainly influenced by both internal and external factors such as cleanliness, fresh food and location. Also the availability of Kenyan dishes attract more customers in restaurants, while the presence of food vendors is the greatest challenge facing the growth of restaurants. With a more favorable government policy and concerted effort by restaurant operators to grow their businesses, they can contribute positively in the Kenyan economy.

Key words: Growth, Small-scale resturants
\end{abstract}

\section{Background information}

Small and Medium Enterprises (SMEs) comprise the largest proportion of businesses in most economies and frequently offer the greatest potential for job creation ( Asquith and Weston, 1994). In the United States Small businesses employing less than twenty people were the major sources of new jobs during the late 1980's (Philips, 1993). A similar pattern was observed in Canada where the fastest growing sector of the economy was that of SMEs (De-Laurentiis, 1994). In Australia SMEs account for about half of the total employment and contribute more to job creation than large-scale businesses (DFAT, 1995). The SMEs promote innovation and inventions (McCormick, 1996) and they employ labor intensive technology that is relevant in developing countries.

One of the key strategies in national development in Kenya is the promotion of SMEs (Republic of Kenya, 1992). In Kenya SMEs employ up to 20 employees and restaurants fall under SMEs (Parker and Torres, 1194, McCormick, 1996). Hotels and Restaurants in Kenya are divided into four categories namely: class A, B, $\mathrm{C}$ and D. Class A is constituted of registered and licensed restaurants that offer food and beverages. Class $\mathrm{C}$ is constituted of restaurants and hotels that offer food, beverages and entertainment. Class D is constituted of hotels that offer food, beverages, accommodation and entertainment. This study focused on class A category of restaurants only. Class A category of restaurants was further divided into small, medium and large restaurants. Small restaurants employ lee than five employees; medium restaurants, 6-15 employees and large restaurants employ over 15 employees. As at $30^{\text {th }}$ June 2002 there were 476 restaurants in class A category in Nakuru Municipality (Nakuru Municipal Office, 2002).

Kenya like many developing countries suffers from the problem of high population growth, unemployment, low investments and low levels of industrialization that lead to low levels of economic growth (Republic of Kenya, 1986). Kenya's population grows at $2.4 \%$ per annum and is expected to be over 35 million by 2003. This implies that it is necessary to double the number of jobs generated yearly. Kenya's arable land is only $18 \%$ of the total land area and $4 / 5$ is either arid or semi-arid. Land is not elastic to population growth (Republic of Kenya, 1989).

By 2003, 20 million jobs will be required in Kenya. With only moderate growth of employment in the modern wage sector, an increasing number of people will have to settle down to SMEs whose share as a proportion of total employment is expected to rise from $7.1 \%$ in 1993 to $13 \%$ in 2000 (Republic of Kenya, 1989). They account for the largest share of employment in the private sector especially in Africa. Surveys indicate that firms with fewer than 10 employees employ 59\% of total private sector employment in Kenya (Yide, 1990). SMEs are attractive to most people because they are labor intensive, require the low initial capital and there is ease of entry (Wickham, 2000). 
Kebiri (1993) findings indicated that restaurants in the hotel industry have a potential for tourism development in Kenya. The restaurants in the tourism sector in Kenya contribute 18\% of foreign exchange and $11 \%$ of GDP (Kenya Utalii collage, 2002). Hotel and restaurants in Kenya promote the tourism industry by generating 30\% of jobs linked to the industry (Kenya Utalii collage, 1999). Hotels and restaurants in Lamu district promote the agricultural sector that in turn supports $80 \%$ of the Districts population (Kenya Utalii collage 1988). The presence of hotels and restaurants facilitate the exploitation of tourism (Barani management team, no date)

Kenya hopes to industrialize by the year 2020 (republic of Kenya 1996), however, it might not achieve this objective due to slow growth and massive failures of SMEs (Livingstone, 1975, Neshamba, 2000). The reason for slow growth and massive failures may not be attributed to lack of capital or environment because the government has tried to alleviate this (World Bank, 1989). This leaves other factors as the principle explanation for the slow growth and massive failures for SMEs.

\subsection{Statement of problem}

Food and hospitality sector is an important part of SMEs in Kenya. Restaurants in particular create employment and market for agricultural sector among other major contributions. Most studies indicate that most SMEs experience poor growth, however, restaurants have not adequately addressed factors that influence the growth of restaurants in Kenya. Better knowledge of what influences the growth will help improve the contribution of this part of SME sector to the national economy.

\subsection{Purpose of study}

The purpose of this study was to identify the factors that influence the growth of class A category of restaurants in Nakuru municipality. Class A category of restaurants constitute of those restaurants that have licenses, permanent premises and only offering food and soft drinks. The factors identified in the conceptual framework model acted as a guide for this study.

\subsection{Objectives of the study}

1. To identify the factors influencing growth of restaurants in nakuru municipality.

2. To identify challenges facing restaurant managers in nakuru municipality

\subsection{Research questions}

1. What are the factors influencing the growth of restaurants in Nakuru municipality

2. What are the challenges facing restaurant managers in nakuru municipality?

\subsection{Significance of the study}

Small and medium Enterprises (SMEs) comprise the largest proportion of businesses in most economies and frequently offer the greatest potential for job creation (Asquith and Weston, 1994). The 20022003 government budgets allocated twenty million shillings for the promotion of SMEs in Kenya. If there is need to improve tourism and government revenue, one must direct attention to the factors influencing the growth of hospitality industry.

The findings of this study may help restaurant owners to identify the problems facing their businesses and institute creative measures aimed at stimulating performance and growth. Business consultants may benefit from improved quality services offered to restaurant owners. The trainers in the hospitality industry may use the results to develop a more effective curriculum whereas policy makers in the industry may use it to develop better policy for the benefit of a healthier hospitality sector. The study may form a basis for further research into more factors that influence the growth of restaurants.

\subsection{Assumption of the study}

1. Small and medium enterprises were pursuing growth objectives.

\subsection{Limitations of study}

(i). The sample size may not have been representative enough of the small-scale restaurants due to its small size.

(ii). Most of the respondents were not conversant in English and this called for the translation of the questionnaire to Kiswahili. In the process some of the original meanings could have been distorted.

(iii). Most of the respondents hesitated to discus items touching on finance.

\subsection{Definition of terms}

Restaurant: it is a formal business with a license, permanent premises and only selling food and soft drinks. 
Growth: will me defined by the number of employees, turnover and organizational structure that involve the challenges that must take place as the business moves from being small to medium size.

Class A category of restaurants. Those that have licenses, permanent premises and only selling food and soft drinks

Economies of scale: These are advantages enjoyed by a business firm as it expands its business operations such as accessibility of finance

Flexible specialization: It is a situation where a firm sub-contract activities that non-core to it.

Inter-firm relationship: It is the transfer of technology from large firms to small - scale firms.

Customers: they are people who seek for services in a restaurant.

Working class: these are medium-income earners.

Infrastructure: this refers to water, roads, electricity, security, telephone services and sewerage services.

\subsection{Introduction}

\section{Literature Review}

This chapter reviews literature in the area of growth of Small and Medium Enterprises. It also discusses other variables related to the study. The chapter finally concludes with a conceptual framework as a basis of this study.

\subsection{The process of growth}

The growth of SMEs in Kenya cannot adequately appreciated without some knowledge and understanding of the term growth. Thus from the onset it is important that we are about what is meant by the term. In the context of this study growth will be defined by the number of employees, turnover and organizational structure that involves the changes that must take place as the business moves from being small to medium size. A number of researchers have measured growth in different ways such as sales, number of customers, profits, number of new products introduced, and number of people employed (Davies, 1987). None of these options presents itself as the most appropriate measure. Depending on the business, a combination of these may be more significant.

\subsection{The importance of growth}

Growth enables a firm to enter new markets and take on competitors. Growth of a business enterprise involves development and change within the organization and changes in the way in which the organization interacts with its environment (Wickham, 2000). Growth of SMEs facilitates the creation of employment and technological advancement (Mugo, 1991). Davies (1987) holds that growth facilitates the development of an economy, enables businessmen to adopt new techniques of management, enable business to gain dominance over the market and also facilitates diversification of products. Holt (2001) research findings found alout that growth enables a firm to expand its sales operations and assets base.

Riethmuller (2000) holds that growth facilitates the development of transport and communication and enables the firm to adopt foreign techniques of production. Growth of SMEs enables citizens of an economy to improve their standards of living through creation of employment (Stanlake, 1985). The output of an economy is improved through growth. Growth is the engine of economic prosperity and its benefits multiply from generation to generation (Shapiro, 1988). Business growth and transformation is an important entrepreneurial activity since it involves new combinations that may lead to the creation of new industries. Business growth like change may be conceptualized as either an entrepreneurial process or an outcome (Neshamba, 2000). Although there is lack of an agreed substantive theory of growth and owners manager ship, according to Schumpeter (1934), there are a number of agreed paradigms, some of which include:

- Growth is necessary for economic well being

- Innovation is necessary for growth.

- Certain environments are more conducive to growth and entrepreneurial activity than others. In developing countries the growth of Small and Medium Enterprises has been faced by obstacles such as misuse of natural and human resources, trade restrictions and high population growth rate (McCormick, 1996).

\subsection{The growth of SMEs in Kenya}

In Kenya as in many African countries, SME sector has been the response to stagnating employment growth in the formal economy, the downsizing of parastatals and of private companies as they reduce costs in a liberalizing environment (Mazzarol, 1998). In Kenya these casual factors are combined with one of the fastest population growth rates in the world requiring the economy to absorb annually about 500,000 new labor market entrants. It is estimated that today, Kenya's SME sector constitutes $90 \%$ of all businesses in the country, absorbs annually up to $50 \%$ of new non-farm employment seekers, has an employment growth rate of $12-14 \%$ and contributes $30 \%$ of total employment and 3\% of GDP (Riley, 2002). 
The acquisition of relevant vocational, technical and business skills is generally regarded in Kenya as one of the critical factors necessary for growth of SMEs. For this reason the policy of providing technical and vocational training at the primary and secondary levels has been in place since 1986 when SMEs sector emerged as one of the key strategies in Economic management and Renewed Growth (ICEG, 1999).

In 1990 the first master's degree programme in entrepreneurial was introduced in Kenya Technical Teachers College (KTTC) and latter moved to Jomo Kenyatta University of Agriculture and Technology with the aim of producing trainers, researchers, administrators with skills in entrepreneurship and promotion of enterprise growth (ICEG, 1999).

In Sessional paper Number 2, 1992; "Small enterprise and Jua Kali Development in Kenya," the government identified the small-scale and Jua Kali enterprises sector for support and assistance to enable it graduate into the formal sector. Its policy action recommendations has spurred the establishment of a wide array of programmes in small enterprise and entrepreneurship growth at many institutions such as Kenya Institutes of Management and Kenya Women Finance Trust.

The Seventh National Development plan (1994-1996) stipulated a strategy for promoting an enterprise culture in Kenya. In 1998 the Ministry of Local Government introduced a single business permit, which was effective on optional basis from January 1999 but mandatory in all-local authorities from January 2000 (ICEG, 1999). Its effect has been to ease the licensing process for business operators.

\subsection{The growth cycle of SMEs}

Small and Medium (SMEs) comprise the largest proportion of business in most economies and frequently offer the greatest potential for job creation (Asquith and Weston, 1994). Churchill and Lewis (1983) have proposed a five-stage model of SMEs growth incorporating Start-up, Survival, Growth, Take-off and Maturity.

\subsubsection{Start-up stage}

During the first stage, the business is conceived and established and all the attention is given to finding customers and maintaining adequate cash flows to survive. The owner is the most important asset of the business providing all its managerial skill, direction and capital.

\subsubsection{Survival Stage}

If the business survives the first stage it graduates to the second stage that is survival stage. During this period the business is financially viable and may even hire additional staff. The owner usually remains in control of the business and undertakes only minimal formal planning (Churchill and Lewis 1983). Many SMEs continue to operate in this stage for long periods of time, with a single or limited product line and any growth being driven by natural market expansion (Scott and Bruce, 1987).

\subsubsection{Growth stage}

From the perspective of growth it is the growth that may be most critical. Churchill and Lewis (1983) also refers to it as "success" period. Here the business is economically strong and has sufficient size and product market penetration enabling it to sustain its current position. Its size is such as to require professional managers. In this stage the owner manager makes a decision to either grow or not. The business is usually profitable and can either continue on its present form or be sold at a profit (Scott and Bruce, 1987). The most crucial stages of a firm are survival stage and growth stages. Some of the challenges faced by a firm in the process of graduating from survival to growth stage include competition, lack of raw materials, lack of marketing competency, lack of credit facilities, low level inventory, small premise size, lack of skilled manpower and poor infrastructure.

\subsubsection{Take-off Stage}

A successful growth strategy will take the business into the fourth stage of "Take Off" or "Expansion". In this critical stage the business will either succeed and develop into a big business or not. As it grows the business will become more formalized in its accounting, management and other systems.

\subsubsection{Maturity stage}

The fifth and final stage of "Maturity" or "Resource maturity" sees the business with sufficient resources to conduct formal strategic planning. Its management structure is likely to be decentralized and there is a greater separation between the owner and the business, in terms of financial and operational matters (Scott and Bruce, 1987). Large Scale investment in marketing and production facilities during this stage may result in additional equity financing. Many SMEs experience difficulties with pressure from shareholders over strategic directions (Churchill and Lewis, 1983). 


\subsection{The factors influencing the growth of SMEs}

Growth is influenced by key internal and external factors that must be considered by entrepreneurs as they move through their growth cycle. Internal factors are those that originate from the firm such as human experience, leadership, managerial skills and owners capabilities. External factors are those that originate from the environment such as finance, technology and government incentives (Vernon, 1980).

Riley (2002) research findings found out access to technical and managerial training, access to finance, involvement in technological innovation and creation of positive enabling environment are they key elements in the growth strategy. Financial issues, education and training and availability of incentives are some of the factors that facilitate growth of SMEs (Carter, Ennis, Lower, Tagg, Webb and Tzokas, 2000). According to the World Bank (1993) approximately 66\% of the observed growth in the SME sector can be attributed to the accumulation of physical and human capital, and education. Human capital refers to skilled labor that is labor that functions on a higher level and has the ability to create new ideas and new methods in economic activity (Rae, 2000). Stanlake (1985) identified increasing skills, education investment, economies of scale, new technology and reallocation of resources as some of the major factors that influence the growth of a firm. (Hyman, 1996) research findings found out that appropriate skills, improvement in technology and productive resources such as capital influence the productive potential of a business. Vernon (1980) identified the major sources of growth as capital input, labor input, advances in knowledge, improved resources allocation and economies of scale. According to Wickham (2000), finance, the organization structure and the strategies adopted by an organization determine its growth.

Khan (1999) argues that factors inputs such as capital, education and training are associated with growth in a firm. Holt (2001) research findings indicated that the education level of the business owner contributes significantly to its growth. GEMINI (1991) holds that capital accumulation and technological advancement contribute to firm's growth. Venture capital is a seminal for growth and job creation (Mazzarol, 1998). Business development services that include auxiliary services provided to SMEs enable the owners to improve and promote the performance of their businesses (Ngugi, 2000). McCormick (1996) research findings identified weak and fluctuating demand as the chief reason why small firms fail to grow. The level of customer demand particularly from high student population who spend much of their disposable income on eating out is an important factor influencing growth of the hospitability industry (Pissarides, et al 2001). The growth of the catering industry has been associated with on-the-job training (anonymous, 2001). Education, better marketing, more resources and availability of Internet services have facilitated the growth of the minority owned businesses (khan, 1999). In the hospitality industry the quality of restaurant food on whether it was prepared the way customers ask for it and menu variety influence the performance of this industry (De-Laurentiis, 1994). The hotel industry in Kenya has grown to the size it is today due to efficient management and a continuity in the service and quality of food (Kenya Utalii college, 2000). The performance of hospitality industry is influenced by quality, freshness, taste, price, convenience, design of packaging, nutritional value of the product and the quantity of the product (Riethmuller, 2000). Carter et al (2000) identified access to funding, training and frequent alterations of the premises as some of the major factors set to shape the hospitality industry.

Havenga, (no date) and Onyuma (1997) suggest that for small firms, geographical location is an important factor for growth. According to Havenga small firms can reap the benefits of division of labor by clustering together that results in efficiency and flexibility gains. Flexible specialization and inter-firm relationship facilitates the growth of SMEs (McCormick, 1996). Neshamba (2000) has identified a number of themes in research which focuses on the owner/manager and which have an impact on business growth such as psychological or personal traits, the need for achievement, risk taking, locus of control, independence innovation and creativity. Rae, (1997) contends that a small business needs business information to facilitate growth. In rapid-growth of a business, the owner/manager is the key factor not only in the founding of the firm but also in the rough and tumble process of running and growing of the firm (Neshamba, 2000).

\subsection{The conceptual Framework}

The conceptual framework model on the factors influencing the growth of small firms will be adopted for this study as demonstrated in the following diagram. 


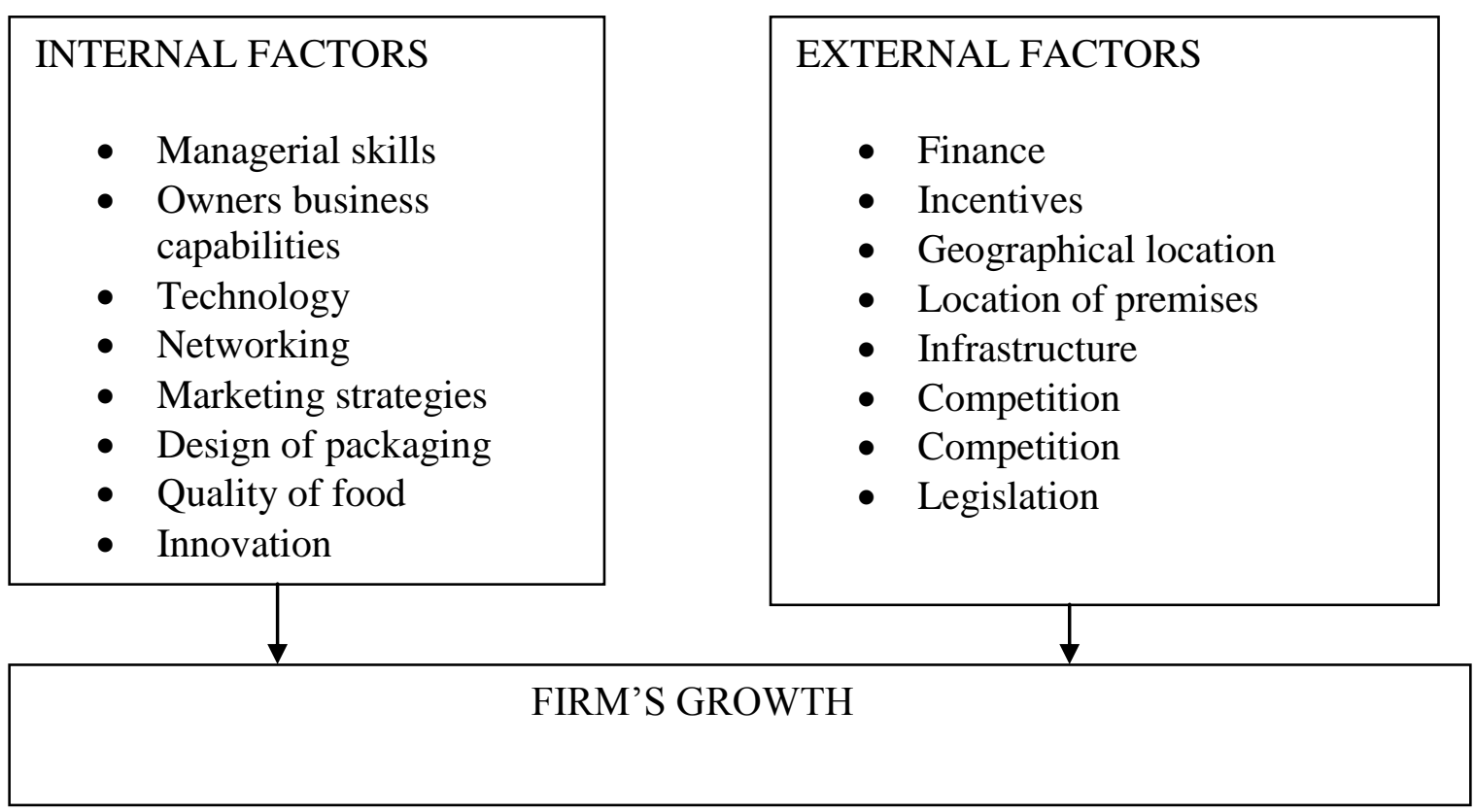

Figure 1 Factors influencing the growth of small firms

The conceptual framework model that the factors influencing the growth of small firms can be divided into two broad categories namely internal and external factors. Internal factors are those that originate from the firm such as managerial skills, capabilities of the owner, technology adopted, business advice and Internet services. External factors are those that emanate from the environment such as finance, government incentives, and economies of scale, location of premises, and geographical location. The above conceptual framework was used in the development of the research instruments.

\subsection{Introduction}

\section{Research Methodology}

This chapter discusses the research design used in the investigation, the target population, sampling procedures, types of instruments used, validation procedures, data collection procedures, and data analysis techniques.

\subsection{Research design}

A survey research design was chosen for this study because it enables the use of descriptive statistics and explanations for analysis. This method is suitable where the phenomena under investigation can be observed directly by the researcher (Borg and Gall, 1989). In this study the population of restaurants was large and hence the suitability of the design.

\subsection{Location and population of the study}

The population of the study consisted of restaurants with licenses, permanent premises and selling food and soft drinks to customers in Nakuru Municipality. Nakuru Municipality is in Nakuru District, Rift Valley Province. Nakuru Municipality is divided into five trading zones namely; Central Business-Center, Biashara Kaptembwo, Lanet, Langalanga-Lake-view and Industrial Area-Showground. The restaurants in this study were distributed in the five zones.

There were 476 restaurants in class A category as at $30^{\text {th }}$ June 2002 (Nakuru Municipality Office, 2002), and this was the target population. Class A category of restaurants was further divided into Small, Medium and Large-scale categories. The small-scale employ less than five employees, medium, 6-12 employees and large-scale 13-20 employees. Of the 476 restaurants making the population in the study 266 were smallscale, 114 medium and 96 were large scale.

\subsection{Sample and sampling procedure}

The population consisted of 476 restaurants and was further divided into three strata namely small, medium and large respectively. Due to limited time and resources only $16.8 \%$ i.e. 80 restaurants formed the sample. Using stratified random sampling similar to Gupta and Gupta (2001), the three strata were sampled as shown below in Table 1. 


\subsection{Instrumentation}

The factors influencing growth of the SMEs discussed in the literature review were used to design the questionnaire. The questions designed were inclusive enough to allow respondents to focus directly on the major growth factors. The questionnaire consisted of both structured and open-ended questions. The questions were administered to managers or owners of restaurants. Only one questionnaire set was used.

\subsection{Validity}

The validity of the instruments was assessed based on the purposefulness and appropriateness of language by experts in the Faculty of Commerce. Experts in business and management checked the content and construct validity of the questionnaire.

\subsection{Data collection procedure}

To achieve the objectives of the study data was collected from selected restaurants in Nakuru Municipality. Both primary and secondary data was collected using a questionnaire administered to both structured and open-ended questions. The researcher trained two assistants who assisted in the collection of the data. The researcher and her assistants distributed all the questionnaires within three days and requested the manager or the owner to fill-in the required information within four days. After four days the researcher and the two assistants went round collecting the completed questionnaires. Interviews were conducted where the manager/owner of the restaurant was not able to complete the questionnaire and on issues that required further clarification. Where the questionnaire was not ready for collection the researcher and her assistants made arrangements for another appointment with the manager or the owner. Secondary data was obtained from government publications, publications of research organizations, trade and professional bodies, Nakuru Municipal office, Ministry of Trade and Commerce and the office of Small and Micro Enterprises. Data collected over a one-month period. Some of the problems encountered include failure by managers/owners to honour the appointments, suspicion on the data and illiteracy.

\subsection{Data analysis}

The data collected was subjected to appropriate statistical analysis using Statistical Package for Social Sciences (SPSS) computer package. The results of the data analysis were used to establish the contribution of the stated factors in the growth of restaurants in Nakuru Municipality.

\subsection{Introduction}

\section{Results And Discussion}

The objective of this study was to establish the factors influencing the growth of restaurants in Nakuru Municipality. A sample of 80 restaurants was visited and interviewed by the researcher and her assistants. There were two main objectives of this study and the results are presented according to each objective.

\subsection{Factors influencing the growth of small-scale restaurants in Nakuru Municipality. 4.2.1 Incentives offered by the government}

As regards the incentives given by the government, the results are given in Table 2 below.

The results show that the government is not perceived to offer incentives by $65 \%$ of owners/managers. The government is perceived to provide infrastructure by $21.25 \%$ of the respondents and others $13.75 \%$ that include incentives such as business loans and grants. Infrastructure refers to water, roads, electricity, security, telephone services and sewerage services.

\subsubsection{Factors contributing to the success of restaurants}

The respondents identified the following factors as major contributors to the success of their restaurants: cleanliness $(38.75 \%)$, fresh food $(33.75 \%)$, location $(31.25 \%)$, commitment and traditional dishes (12.25\%) each, variety of dishes (7.5\%) and others (16.25\%) that include factors such as effective supervision and availability of toilet facilities.

\subsubsection{Preferred dishes}

Table 3 shows the dishes preferred by most customers

Table 3 shows that most customers prefer Kenyan dishes that account for $96.3 \%$ of all the dishes with traditional dishes accounting for $2.5 \%$. The customers do not prefer Asian, Indian and Arabic dishes.

\subsubsection{Reasons for frequenting particular restaurants}

Table 4 below shows views of managers/owners why most customers frequent particular restaurants. 
Table 4 shows most customers visit restaurants that offer fresh food accounting for $27.5 \%$. Other reasons why customers frequent restaurants are cleanliness $(12.5 \%)$, availability of Traditional dishes $(8.8 \%)$, and others such as low prices and ample space account for $34.3 \%$. This shows that fresh food seems to be the main factor that attracts customers in restaurants followed by cleanliness, Location and availability of traditional dishes.

\subsubsection{Location of Restaurants}

Table 5 below shows that most restaurants are located on the main street (45\%). Those located off the main street accounted for $3705 \%$. The other preferred locations are upstairs $(8.8 \%)$, at the petrol stations $(2.5 \%)$ and others such as at the residential areas (6.3\%). The main street and off-the main street are the most preferred locations by managers/owners.

\subsubsection{Qualifications of managers/owners}

Table 6 below shows that most managers/owners are certificate holders and this accounts for $71.3 \%$, diploma holders $(18.8 \%)$, graduate $(7.5 \%)$ and others such as a primary education and secondary education account for $1.3 \%$.

\subsubsection{Training}

Table 7 below shows that $73.8 \%$ of restaurants do not offer training to their employees. Only $25 \%$ offer training to their employees.

\subsubsection{Courses offered by managers/owners.}

The courses offered by managers/owners are shown in table 8 below.

The results show that customer care and food production both account for 30\% each, cookery and catering (15\%) each and others such as Business Management, Business Administration and hotel management account for $10 \%$.

\subsubsection{Sources of finance}

Table 9 shows that personal savings constitute the major source of finance for start-up accounting for $71.3 \%$, bank loan (12.5\%), co-operative loan (5.0\%), borrowing from friends (3.8\%) and others such as grants, non-governmental organizations assistance accounts for $6.3 \%$

\subsection{The challenges facing restaurant managers/ owners in Nakuru municipality. 4.3.1 Managers responses and dissatisfaction by customers.}

The results show that most managers/owners respond differently to the complaints aired by customers. Most managers/ owners offer replacement for a meal, a snack or a drink to customers and this account for $51.25 \%$. other responses to this problem include apologizing (21.25\%), effective supervision (18.75) installation of a suggestion box $(6.25 \%)$ and others such as re-evaluation of services account for $12.5 \%$

\subsubsection{Trends and turnover, expenses and employees from their initial state.}

The items assessing the trend of turnover, expenses and the number of employees all indicate that the three had increased in most restaurants. The turnover had increased in 48 restaurants while it had declined in 20 restaurants. The expenses ha increased in 45 restaurants while it had declined in 21 restaurants. The number of employees had increased in 50 restaurants while it had declined in 18 restaurants.

\subsubsection{Problems facing restaurants managers/owners.}

The results indicate that the presence of food vendors along the streets is the major problem accounting for $75 \%$. The others include poor infrastructure (37.5\%), liberalization of the economy (31.25\%), high rates of inflation $(26.25 \%)$, high cost of inputs $(25 \%)$, high taxes $(25 \%)$, corruption $(15 \%)$ and others such as stiff competition, default in payments and removal of signboards by municipal employees accounting for $12.25 \%$. most managers/owners who were interviewed complained that food vendors operate their businesses at their doorstep thus affecting their daily sales. Food vendors also do not pay licenses and chance they compete unfairly with restaurants. The high rate of inflation has made many people to reduce their expenditure on food and this has affected restaurants. Poor infrastructures especially lack of water in the Municipality affects the operations of restaurants. High cost of inputs such as potatoes and meat affect the volume of their businesses. High taxation by the government also affects the performance of restaurants. Liberalization of the economy has either led to retrenchment or closure of many industries thus rendering many people unemployed. This affects restaurants whose major customers constitute the working class. Bad governance through practices such as corruption has increased operating expenses of restaurants. 


\subsection{4 age of managers/owners}

The structured items generated more information on the challenges facing restaurants in Nakuru municipality. Table 10 below shows that most restaurants are managed by managers/owners of aged between $25-55$ years accounting for $77.6 \%$. those below 25 years $15 \%$, and those above 55 years, $7.5 \%$.

\subsubsection{Gender}

Table 11 shows, that most restaurants are managed by male, $(66.3 \%)$, while female managers account for $33.8 \%$.

\subsubsection{Category of customers.}

Table 12 below shows that the working class constitutes the major customers of restaurants in Nakuru municipality $(43.8 \%)$. Working class refers to medium-income earners. The other sources of customers are travelers, $27.5 \%$, families $12.5 \%$, and the youth, $11.3 \%$.

\subsubsection{Financial aspect affecting restaurants.}

Table 13 shows that high inflation rate poses the greatest threat to accessibility of finance to restaurant managers/owners accounting for $72.5 \%$, with others including high interest rates (11.3\%), lack of collateral $(5 \%)$, lack of guarantors $(1.3 \%)$ and others such as handling of outdated cheques accounting for $6.3 \%$

\subsubsection{Harassment by government officers}

Table 14 shows that $42.5 \%$ of restaurants managers/owners complained of harassment by government officers, while $11.3 \%$ complained of bribery cases by the government officers. Harassment refers to illegal activities administered by municipal employees on restaurants such as confiscation of property and condemnation of restaurants on poor hygiene basis unfairly.

From the finding the government is not assisting SMEs to grow due to lack of incentives. Despite government assistance in providing infrastructure, $15 \%$ of the respondents still feel that provision of good infrastructure can contribute significantly to the success of restaurants in Nakuru municipality. The main source of finance for restaurant operations is personal savings despite the various international and local nongovernmental organizations and government initiated programs such as Kenya Industrial Estate and Industrial Development bank initiated to assist SMEs. Most restaurant managers/owners are qualified in that most of them have attained certificates, but they do not offer further training to their employees in restaurant management related courses despite many Non-Financial Promotional Programs initiated in Kenya to assist in training of managers and employees of SMEs.

The results also show that the presence of food venders along the streets is the major challenge facing restaurant managers/owners in Nakuru municipality despite the government effort to settle them through various programs such as the Jua kali sector. Most restaurants are managed by young managers of ages between 26-45 years unlike in the past where elderly managers dominated the industry. Despite the government emphasis on equal opportunities between male and female, the management of restaurants in Nakuru municipality is still dominated by male counterparts accounting for $66.35 \%$. Harassment that refers to unfair treatment by municipal employees to restaurants owners such as confiscation of property is still a major challenge facing the hospitality industry despite the government effort to encourage SMEs that constitute the major employer in developing countries.

The implications of this study that; entrepreneurs contemplating to invest in the hospitality industry should consider both internal and external factors influencing its growth. The entrepreneurs should also be ready to face the many challenges in the industry.

\subsection{INTRODUCTION}

\section{Conclusion And Recommendations}

This study aimed at investigating the factors the growth of small-scale restaurants in Nakuru municipality. This chapter presents a summary of the major findings, conclusions, recommendations and suggestions for further research.

\subsection{SUMMARY OF THE MAJOR FINDINGS}

On the basis of data analysis, the following are the major findings arising from this study.

(i). The small-scale restaurants in Nakuru municipality have been growing in terms of employees, turnover and expenses.

(ii). The growth of small-scale restaurants is influenced by both internal and external factors such as cleanliness, availability of fresh food, commitment of employees and location.

(iii). The availability of Kenyan dishes attract more customers in restaurants. 
(iv). The presence of food vendors along the streets of Nakuru municipality is the greatest challenge facing restaurant owners.

(v). Poor infrastructure in Nakuru Municipality is one of the major constraints affecting the growth of restaurants in Nakuru Municipality.

(vi). Most restaurants do not offer in-service courses to their employees.

\subsection{COCNCLUSIONS}

The major focus of this study was to investigate the factors influencing the growth of small-scale restaurants in Nakuru Municipality. The findings of the study indicate that the growth of small-scale restaurants in Nakuru Municipality is influenced by both internal and external factors. The internal factors identified in this study include quality of food, cleanliness, effective services, availability of variety of dishes and offering of fresh food. The external factors include finance, competition, infrastructure, legislation and location of premises. The availability of fresh food, offering the efficient services, variety of dishes and cleanliness all contribute to attracting and retaining customers in restaurants.

The major challenges facing small-scale restaurants in Nakuru municipality are also identified in this study. They include food vendors along the streets, poor infrastructure, liberalization of the economy, high rate of inflation, high cost of inputs, high taxes and corruption. The presence of food vendors along the streets affects the volume of restaurant businesses because the vendors offer their products at lower prices than restaurants but of the same quality. Poor infrastructure inform of unreliable water supply, high cost of electricity, poor sewerage services, seasonal roads and high telephone bills all increase operation expenses in restaurants. Liberalization of the economy either leads to retrenchment or closure of industries that minimizes the number of working class who constitute the major customers of restaurants. Inflation, high cost of inputs, high taxes and corruption cases all influence the operations of restaurants.

\subsection{RECOMMENDATIONS/SUGGESTIONS}

(i). There is an urgent need to address the issue of food vendors who constitute the major challenge facing restaurant owners.

(ii). The government should encourage non-financial and financial promotional programs aimed at assisting SMEs.

(iii). The government should provide an enabling business environment that is supportive, facilitative and favorable for business activities to thrive.

(iv). There is need to restructure the tax system in order to incorporate food vendors.

(v). There is need to provide good infrastructure in term of reliable water supply, affordable electricity, cheap telephone services, accessible roads and good sewerage system in order to ensure offering of efficient services by restaurant owners.

(vi). There is need to create conditions for economic growth in order to generate employment for the citizens, who constitute the major customers of all small-scale restaurants in nakuru municipality.

(vii). Restaurants should maintain cleanliness, high quality products, and freshness in order to attract and retain customers.

(viii). Restaurants owners should be encouraged to offer training to their employees.

\subsection{SUGGESTIONS FOR FURTHER RESEARCH}

From the findings of this study there is need for further research in the following areas.

(a) A large sample incorporating small-scale restaurants in Nakuru Municipality could be studied to consolidate what is considered as major factors influencing the growth of these enterprises.

(b) A study could be carried out on food vendor's issue in order to find out what can be done to alleviate the unfair competition between them and restaurant owners.

(c) A study can be done on the nature of corruption as a constraint.

\section{References}

[1]. Anonymous, (2001). "Regional Market Details" Available @ http://www.careers.co.nz/jobs/5b hos/80302r.htm

[2]. Asquith, D and Watson, F., (1994). "Small business, growth patterns and jobs", Business Economies Vol. 29, No. 3, July, p: 31-34.

[3]. Barani Nobel Management Team, (no date). "Feasibility Study." Mombasa, Kenya.

[4]. Borg, W.R and Gall, M.D., (1989). "Educational Research". An introduction. Longman Inc New York, USA.

[5]. Churchill, R. and Lewis N., (1983). "The Five Stages of Small Business Growth", Harvard Business Review, May/June, Vol. 61, No. 3. P: $30-50$.

[6]. Carter, S., Ennis, S., Lowe, A., Tagg, S., Tzokas, N., Webb, J., and Andriopoulous, C., (2000). "Barriers to survival and growth in U.K small-firms". Report to the Federation of small Businesses available @ http:www:marketing.strath.ac.uk.

[7]. Davies, S., (1987). "Women and Small Enterprises Creation". Rout ledge, London

[8]. De-Laurentiis, J., (1994). "Beyond the bounds of traditional lending”, Canadian Business Review, Vol. 21, No. 1, spring, p: 19-21.

[9]. Department of Foreign Affairs and Trade (9DFAT) (1995). "Winning Enterprises". 
[10]. How Australia's small and medium enterprises compete in global markets, Australian Government Publishing Services, Canberra, Australia.

[11]. Gemini, (1991). "Micro and Small-scale enterprises in Zimbabwe". Results of a countrywide survey, GEMINI Technical Report, No. 25, Dec 1991, Zimbabwe.

[12]. Gupta, S.P. and Gupta, M.P., (2001). "Businesses Statistics”. Pg 539. Sultan Chad and Sons, New Delhi, India.

[13]. Havenga, K., (no date). "Human Capita and other important factors as elements of entrepreneurship and SMEs in developing countries",

[14]. Holt, D.H., (2001). "Entrepreneurship. New venture creation”. Prentice of India, New Delhi.

[15]. Hyman, D., (1996). "Macro Economics". $4^{\text {th }}$ Edition Irwin, USA. International Center for Economic Growth, K-Remp and KBS, (1999). "National Baseline and Survey" Micro and Small Enterprise in Kenya. Nairobi, Kenya.

[16]. Kebiri, A., (1993). "Employment generation in hotel catering and tourism sector", Kenya Utalii College, Nairobi, Kenya.

[17]. Kenya Utalii College, (1988). "Tourism Development plan for Lamu Archipelago”.Nairobi, Kenya

[18]. Kenya Utalii College, (1990). "a case study on management of resources". Nairobi, Kenya.

[19]. Kenya Utalii Collage, (2000). "Facing up to the Social Economic changes that impact on the demand and supply of hotel products and services". Nairobi, Kenya.

[20]. Kenya Utalii Collage, (2002). "Poverty reduction strategy paper". Medium term expenditure framework, tourism sub-sector monitoring and evaluation report. Nairobi, Kenya.

[21]. Khan, R., (1999). "Minority owned businesses on the rise throughout state", San Angelo Standard Times, USA

[22]. Living Stone ian, (1975), "Rural Industrial Development program". An evaluation of expenditure and proposals for Action. IDS working paper. No. 61. University of Nairobi, Kenya.

[23]. Mazzarol, T., (1998). Partnerships a key to growth in Small Businesses", Available @ htt:/www.sbaer.uca.edu/Research/1998/ICSB/aool.htm.

[24]. Mugo, J., (1991). "Determinants of Entrepreneurial performance in small-scale enterprises in Kenya", a case study of Mathira Division Nyeri District. University of Nairobi, Kenya.

[25]. Ngugi, D.M., (2000). "Factors influencing the success of small firms". A case study of Rari Division Kiambu District. University of Nairobi, Kenya.

[26]. Neshamba, T., (2000). "growth and transformation among small businesses in Kenya". United Kingdom.

[27]. Ongile, R.M. and McCormic, D., (1996). "Small Enterprises Flexibility and Networking in African Context". Longhorn, Kenya.

[28]. Onyuma, S.O., (1997). "The restaurant industry. Determinants of location of restaurants businesses in United States". USA

[29]. Parker, J. and Torres, S., (1994). "Micro and Small Enterprises in Kenya": Report of the 1993 Baseline Survey, GEMINI Project, Contact Number DHR5448-q-459081-00

[30]. Pissarides, F., Singet, M.; and Svejnar, J., (2001). "objectives and constraints of Entrepreneurship. Evidence from small and medium size enterprises in Russia and Bulgaria".

[31]. Philips, B., (1993). "the growth of small firm job by state 1984-88". Business Economics, Vol. 28, No.2 April, pg:38-53.

[32]. Rae, D., Ratcheva, V. and Vyakarham, S., (1997). "The role of business information in facilitating growth in small businesses:, Available online @ http://www.nbs.ac.uk/cgb/research/papers/facsmallbus.htm

[33]. Rae, D., Ratcheva, V and Vyakarham, S., (2000). "barriers to growth'. Available online @ http://www.nbs.ac.uk/cgb/research/papers/btg/hym

[34]. Republic of Kenya: "Sessional paper No.1, of 1986 on economic management for renewed growth", Government press, Nairobi, Kenya.

[35]. Republic of Kenya: 'development plan 1989-93”. Government press, Nairobi, Kenya

[36]. Republic of Kenya: 'Sessional paper No.2 of 1992 on small enterprise and Jua kali development in Kenya". Government printer, Nairobi, Kenya

[37]. Republic ok Kenya: "the seventh national development plan 1994-96". Government press Nairobi, Kenya

[38]. Republic of Kenya: Sessional paper No2 of 1996 on Industrial transformation to the year 2020". Government Printer, Nairobi, Kenya

[39]. Riethmuller, P.. and Stroppiana, R., (2000). "factors influencing food demand.: Survey evidence from Japan. The University of Queensland, Japan

[40]. Riley, A.T. and Steel, F.W., (2002). "Training the Business Development Services". Kenya Micro and Small Enterprises Training and Technology Project. Available @ http://www.lo.org/public/english/enmployment/ ent/papers/voucher/htm

[41]. Schumpeter, (1934). "The theory of Economic Development". Harvard University press, USA

[42]. Scott, J. and Bruce, M., (1987). Strategic alliance spur business R\&D. Financier June volume 15 No.6 p: 18-21

[43]. Shapiro, E., (1988). "Micro Economic Analysis". Galgotia Publications, $5^{\text {th }}$ Edition, New York, USA

[44]. Stanlake, G.F., (1985). "Introduction of Economics". $4^{\text {th }}$ Edition, Longman, Hong Kong.

[45]. Vernon, J., (1980). "Micro Economics". The Dryden Press, England

[46]. Wickham, P.A., (2000). "Strategic Entrepreneurship." Prentice Of India, New Delhi, India

[47]. World bank, (1989). "Sub-Saharan Africa: From Crisis to Sustainable Growth." Washington, D.C. The World Bank, USA

[48]. World Bank, (1993). "Report on Kenya's Employment Growth for Poverty Alleviation".14 $4^{\text {th }}$ May 1993

[49]. Yide, O.A., (1990). "Entrepreneurship growth in Sub-Saharan Africa", Evidence policy implication paper prepared for world bank conference on Africa. Economic issues in June 4-7 (1990). Nairobi, Kenya

Table 1. The strata of the sample

\begin{tabular}{lccc}
\hline STRATA & RESTAURANTS & PROBABILITY & SAMPLE \\
\hline SMALL & 266 & 0.5588 & 45 \\
MEDIUM & 114 & 0.2395 & 19 \\
LARGE & 96 & 0.2017 & 16 \\
\hline TOTAL & 476 & 1 & 80 \\
\hline
\end{tabular}


Table 2: Incentives offered by the government

\begin{tabular}{lcc} 
Incentives offered & Frequency & $\%$ \\
\hline Infrastructure & 17 & 21.25 \\
Others & 11 & 13.75 \\
Fotal & 80 & 100 \\
\hline
\end{tabular}

Table 3: Preferred dishes

\begin{tabular}{lcl}
\hline Dishes & Frequency & $\%$ \\
Kenyan & 77 & 96.3 \\
\hline Traditional & 2 & 2.5 \\
Indian & 0 & 0 \\
Asian & 0 & 0 \\
Arabic & 0 & 0 \\
fotal & 80 & 100 \\
\hline
\end{tabular}

Table 4: Reasons for frequenting particular restaurants

\begin{tabular}{lcc} 
Reasons & Frequency & $\%$ \\
\hline Eleantiness & 13 & 16.3 \\
Fresh food & 22 & 27.5 \\
Location & 10 & 12.5 \\
Traditional & 7 & 8.8 \\
Cleanliness and fresh food & 15 & 18.8 \\
Cleanliness and Location & 12 & 15 \\
Fresh food and Location & 1 & 1.3 \\
\hline Total & 80 & 100 \\
\hline
\end{tabular}

Table 5: Location of restaurants

Location Frequency

\begin{tabular}{lcc} 
& Frequency & $\%$ \\
Macins street & 30 & 45 \\
Upstairs & 7 & 8.8 \\
\hline Petrol station & 2 & 2.5 \\
Off main street & 30 & 37.5 \\
Others & 5 & 6.3 \\
\hline Total & 80 & 100
\end{tabular}

Table 6: Qualifications of managers/owners

Qualifications Frequency

\begin{tabular}{llc} 
Diploma & 51 & 18.8 \\
\hline Certificate & 57 & 71.3 \\
Others & 1 & 1.3 \\
Total & 80 & 100 \\
\hline
\end{tabular}

Table 7. Courses offered to employees

\begin{tabular}{lll} 
Options & Frequency & $\%$ \\
Yes & 20 & 25 \\
\hline No & 59 & 73.8 \\
Total & 80 & 100 \\
\hline \hline
\end{tabular}

Table 8: Courses offered by managers/owners

\begin{tabular}{lcc}
\hline Courses & Frequency & $\%$ \\
\hline Customer care & 6 & 30 \\
Cookery & 3 & 15 \\
Catering & 3 & 15 \\
Food production & 6 & 30 \\
Others & 2 & 10 \\
\hline Total & 20 & 100 \\
\hline
\end{tabular}


Table 9: sources of finance

Source of finance frequency $\%$

\begin{tabular}{lllll}
\hline Personal saviligs & & & & \\
Bank loans & 5 & 10 & 5 & \\
Co-operative loan & 5 & & 3.5 & \\
Borrowings from friends & 3 & & 3.8 & 6.3 \\
Others & & 5 & & 100 \\
Total & 80 & & 100 \\
\hline
\end{tabular}

Table 10: age of managers/owners

\begin{tabular}{lll}
\hline Age (years) & frequency & $\%$ \\
Below 25 & 12 & 15 \\
\hline $26-35$ & 21 & 26.3 \\
$36-45$ & 20 & 25 \\
$46-55$ & 21 & 26.3 \\
Above 55 & 6 & 7.5 \\
Total & 80 & 100 \\
\hline
\end{tabular}

Tale 11. Gender.

\begin{tabular}{|c|c|c|c|c|c|}
\hline Gender & Frequency & $\%$ & & & \\
\hline Male & $53-1$ & -66.3 & & & \\
\hline Female 27 & \multicolumn{2}{|c|}{33.8} & & & \\
\hline Total & 80 & 100 & & & \\
\hline \multicolumn{6}{|c|}{ Table 12: category of customers } \\
\hline \multicolumn{2}{|c|}{ Sources of customers' } & \multicolumn{2}{|c|}{ frequency } & \multicolumn{2}{|l|}{$\%$} \\
\hline \multicolumn{2}{|c|}{ Working class } & & 35 & & 43.8 \\
\hline \multicolumn{2}{|c|}{ Youth } & & 4 & & 5 \\
\hline \multicolumn{2}{|l|}{ Travelers } & & 22 & & 27.5 \\
\hline \multicolumn{2}{|l|}{ Families } & 10 & & 12.5 & \\
\hline \multicolumn{2}{|c|}{ Working class and travelers } & & 9 & & 11.3 \\
\hline Total & & & 80 & & 100 \\
\hline
\end{tabular}

Table 13. Financial aspects affecting restaurants operations

\begin{tabular}{lccc}
\hline \multicolumn{2}{l}{ Financial factors frequency } & $\%$ & \\
\hline $\begin{array}{l}\text { High interest rates } \\
\text { Lack of collateral } 4\end{array}$ & 9 & & 11.3 \\
$\begin{array}{l}\text { Lack of guarantors } \\
\text { Inflation }\end{array}$ & 1 & 5 & 1.3 \\
Others & 58 & 72.5 & \\
\hline Total & 5 & & 6.3 \\
\hline
\end{tabular}

Table 14: harassment by government officers

\begin{tabular}{|c|c|c|c|}
\hline \multicolumn{2}{|c|}{ Act of government officers } & Frequency & \multirow[t]{2}{*}{$\%$} \\
\hline Bribing & 9 & 11.3 & \\
\hline Harassment & & 34 & 42.5 \\
\hline Others & & 34 & 42.5 \\
\hline Total & & 77 & 96.3 \\
\hline
\end{tabular}

